\title{
Further Investigations of Actinomycetes by Scanning Electron Microscopy
}

\author{
By S. T. WILLIAMS \\ Hartley Botanical Laboratories, University of Liverpool, Liverpool, L69 3 BX
}

(Accepted for publication 20 March 1970)

\section{SUMMAR Y}

To improve results obtained when examining actinomycetes by scanning electron microscopy, the microscope was operated under conditions giving higher resolution with a reduced but sufficient depth of focus. In addition, fixation and dehydration of specimens before coating reduced the distortion caused by desiccation under vacuum. By these means, representatives of the following genera were examined: Actinobifida, Actinoplanes, Actinopycnidium, Actinosporangium, Microbispora, Microechinospora, Microellobosporia, Planomonospora, Sporichthya, Thermoactinomyces and Thermomonospora. The study revealed points of similarity between Actinopycnidium and Actinosporangium; Microellobosporia and Microechinospora; and Actinobifida and Thermoactinomyces.

\section{INTRODUCTION}

The potential usefulness of scanning electron microscopy in studies of actinomycetes was demonstrated by Williams \& Davies (I967). The technique has now been successfully applied to a variety of microbes. Studies include an ever-increasing number on fungi (Barnes \& Neve, I968; Greenhalgh \& Evans, I968; Hawker, I968; Hawker \& Gooday, I968; Jones, I 968; Old \& Robertson, 1969). Bacillus endospores have been examined by Murphy \& Campbell (1969), bacteria in soil by Gray (1967) and Hagen, Hawrylewicz, Anderson, Tolkacz \& Cephus (1968), blue-green algae by Echlin (1968), and protozoa by Small \& Marszalek (1969). Dietz \& Matthews (1969) have recently studied spore morphology of various Streptomyces species.

Since the initial work on actinomycetes by Williams \& Davies (1967), a large number of strains have been examined and further information on the range of form in this group obtained. In addition, improved specimen preparation and instrument operation have resulted in better resolution at higher magnifications. Some of the results obtained are reported here.

\section{METHODS}

Strains used. These were: Actinobifida alba (CUB 432), A. dichotomica (CUB 339), Actinoplanes sp., Actinopycnidium caeruleum (RIA 729), Actinosporangium violaceum (RIA 655), Microbispora rosea (RIA 477), Microechinospora grisea (LIA 0442), Microellosbosporia flavea (IMRU 3858), Planomonospora venezuelense (ATCC 23865), Sporichthya polymorpha (IMRU 39I3), Thermoactinomyces vulgaris (CUB) and Thermomonospora viridis (CUB). (RIA = U.S.S.R. Research Institute for Antibiotics, Moscow; LIA = Research Institute of Antibiotics, Leningrad; IMRU $=$ Institute of Microbiology, 
Rutgers, New Brunswick, U.S.A.: ATCC $=$ American Type Culture Collection; CUB $=$ Department of Biological Sciences, University of Bradford.)

Media. Actinobifida alba, Thermoactinomyces vulgaris and Thermomonospora viridis were grown on Oxoid nutrient agar; Actinoplanes sp., Planomonospora venezuelense and Sporichthya polymorpha on potato-carrot agar (Cross, Lechevalier \& Lechevalier, 1963); and the rest on oatmeal agar (Waksman, 1961).

Culture methods. Each strain was inoculated both directly on to the surface of the medium and on to coverslips embedded in the medium (Williams \& Davies, 1967). All were incubated at $25^{\circ}$ except Actinobifida alba, A. dichotomica, Thermoactinomyces vulgaris and Thermomonospora viridis, which were grown at $45^{\circ}$, and Microechinospora grisea, which was incubated at $37^{\circ}$.

Preparation for examination. Material grown on both the medium and on coverslips was used, and fixed material as well as untreated was examined. Fixation was carried out by immersing a coverslip or a block of medium $\left(5 \mathrm{~mm}^{3}\right)$ with adherent growth in a I $\%$ solution of osmium tetroxide in buffer for $2 \mathrm{~h}$. at room temperature. After washing three times with distilled water, the material was dehydrated in 50 and $70 \%$ (30 min. each) and absolute ethanol (6o min.)

Coverslips and agar blocks with fixed and untreated growth were attached to metal specimen stubs with adhesive. They were then coated under vacuum with a thin film (about $30 \mathrm{~nm}$.) of gold-palladium alloy.

Examination with scanning electron microscope. Specimens were examined over a range of working magnifications from 5000 to 50,000 times using a 'Stereoscan' electron microscope (Cambridge Scientific Instruments Ltd). The instrument was operated at $20 \mathrm{kV}$ with a beam-specimen angle of $45^{\circ}$ and a working distance of 9 to I I $\mathrm{mm}$. High lens condenser currents $(0.7$ to $0.9 \mathrm{~A})$ were used to reduce the final probe diameter, i.e. to increase resolution. Resulting noise levels on the visual screen were minimized by use of a large $(200 \mu \mathrm{m}$.) final aperture. Remaining noise was removed when photographing by having a long exposure time (200 or $400 \mathrm{sec}$.). Subjects were photographed using Ilford HP 4 film.

\section{RESULTS}

Comparison of preparation methods. Fixation and dehydration of specimens prior to coating eliminated or greatly reduced the distortion of cells caused by desiccation under vacuum which was observed by Williams \& Davies (1967). Comparison of treated and untreated material revealed no changes in surface structures induced by the treatments, although some were observed in Streptomyces spore surfaces (Williams \& Sharples, 1970). Sometimes partial collapse of untreated specimens emphasized surface detail; the firm ridges on spores of Actinobifida and Thermoactinomyces (Pl. 4, fig. 18) were more prominent in untreated material. Some strains, such as Sporichthya polymorpha, were unaltered by desiccation under vacuum and satisfactory results were obtained with untreated material (Pl. 5, fig. 23 to 27).

Information provided by coverslip and agar block preparations varied with the growth habit of the strain. The agar blocks were most useful when fruiting was sparse on coverslips, as for example with Actinoplanes sp. Growth on the blocks was often too dense for accurate observation. Therefore, with some exceptions, best results were obtained from fixed-dehydrated growth on coverslips. 
Examination of genera. Genera studied included a number which formed sporangia. These were Actinoplanes, Microechinospora, Microellobosporia and Planomonospora. In Actinoplanes, both sessile and stalked sporangia were present (Pl. I, fig. I, 2). Sessile sporangia developed on a mound raised above the surface of the medium which was composed of hyphae; these were probably analogous with the palisade hyphae observed in sporangial genera by Couch (I955). The arrangement of spores within the sporangium appeared either columnar (Pl. I, fig. 3) or spiral (Pl. I, fig. 2), but the former could usually be shown to be spiral when viewed from another angle. A young ruptured sporangium (Pl. I, fig. 5) showed the spiral arrangement of the sporongenous hypha which was in association with small pieces of material possibly representing the intersporal substance observed by Lechevalier \& Holbert (1965). Young spores were irregular in shape with occasional pitting of their surface (Pl. I, fig. 4). The sporangial envelope, while present as a close investment of the developing spores (PI. I, fig. 3), was not visible in mature sporangia. At all stages it was possible to see the spores through it; this was not possible with the envelope of Streptosporangium (Williams \& Davies, 1967) and the other sporangia-forming genera studied here. Microellobosporia is characterized by the formation of a short row of two to five spores in a club-shaped sporangium (Cross et al. 1963). A two-spored sporangium is illustrated in P1. I, fig. 6, with its wrinkled sporangial envelope. A similar genus, Microechinospora, differing from Microellobosporia by having a sporangium with spines on its wall and usually containing only one spore, was described by Konev, Tsyganov, Minbaev \& Morosov (1965). Examination of Microechinospora grisea did not reveal any ornamentation of the mostly one-spored sporangia (Pl. I, fig. 7).

Another form of sporangium occurs in a number of recently described genera. This is an elongated structure that releases its spore or spores through the tip, and occurs in Dactylosporangium (Thiemann, Pagani \& Beretta, 1967a), Planomonospora (Thiemann, Pagani \& Beretta, I967 b) and Planobispora (Thiemann \& Beretta, I968). These genera differ mainly in the number of spores formed in the sporangium. The example studied here, Planomonospora, was characterized as having only one spore in the sporangium. Double rows of closely packed sporangia were formed, the sporangia arising directly from a trailing basal hypha (PI. 2, fig. 8, 9). A number of the sporangia appeared to be invested by a more transparent outer sheath that possibly originated from the outer component of the hyphal wall. Tips of the sporangia were at first beaked (Pl. 2, fig. 8) but eventually the ends disappeared leaving a distinct pore (Pl. 2, fig. I I). The pore obviously allowed the release of the elongated spore (Pl. 2, fig. 10) but the only evidence of this was obtained when an irregular mass of material, possibly a ruptured spore, emerged from the pore (Pl. 2, fig. 12). Spore emergence was observed by Thiemann et al. (1967b).

The genus Actinosporangium was described as forming 'pseudo-sporangia' lacking an envelope (Krasilnikov \& Tsi-Shen, 196r). These were formed by the repeated branching and intertwining of a number of hyphae (Pl. 2, fig. I3) which eventually resulted in the formation of large, localized masses of spores and hyphal fragments (Pl. 3, fig. I 4, I 5).

The genus Actinopycnidium was characterized by the formation of pycnidia, 70 to $100 \mu \mathrm{m}$. in diameter, containing spores (Krasilnikov, I962). The pycnidium wall was said to be formed of interwoven hyphae; this, unlike other aggregate hyphal structures, such as sclerotia, was easily ruptured (Baldacci, Locci \& Rogers Locci, 1966). 
Observations here indicated that the 'pycnidium' consisted of a dense mass of spores, formed by the localization of spore production in a manner similar to Actinosporangium. The surface of these masses appeared to consist of spores adhering closely together (Pl. 3, fig. 16, I7).

The production of polygonal spores by Thermoactinomyces vulgaris was observed by Williams \& Davies (1967). Further examination of this and other thermophilic genera has shown that the spores have ridges in Thermoactinomyces and Actinobifida (Pl. 4, fig. I8), but not in Thermomonospora (Pl. 4, fig. I9). The silhouettes of Actinobifida chromogena from the study by Krasilnikov \& Agre (1965) also suggest a ridged structure. Cross, Walker \& Gould (1968) demonstrated the presence of ridges overlaid by an outer sporangial envelope in sections of T. vulgaris and Actinobifida dichotomica and also found that such spores had a high degree of heat resistence. Similar structured endospores are formed by certain Bacillus species and those of Bacillus polymyxa were examined with the scanning electron microscope by Murphy \& Campbell (1969). In young spores of both Actinobifida and Thermoactinomyces the ridges were not visible, spores being evenly covered by a wrinkled outer envelope. (Pl. 4, fig. 20).

The characteristically paired spores of Microbispora were attached to their sporophore in an unusual manner. The tip of the sporophore was expanded to form a platform and the basal spore was invaginated to fit over this in a ball and socket arrangement (Pl. 4, fig. 2I, 22). This structure represents the collar observed by Lechevalier \& Lechevalier (1957) in a silhouette of such a spore.

The genus Sporichthya, described recently by Lechevalier, Lechevalier \& Holbert (I968), has a life cycle unlike that of any other known actinomycete. Detached cells, with a basal collar (Pl. 5, fig. 23) divided to form vertical piles of cells of varying height (Pl. 5, fig. 24). These were formed on the surface of the substrate (in this case glass), the basal cell being slightly inflated to form an attachment to the surface (Pl. 5, fig. 25). The piles broke into single cells, or occasionally a fish-shaped outgrowth from a cell was formed (PI. 5, fig. 26). Branching hyphae were observed infrequently (Pl. 5, fig. 27). When grown on agar media, the same structures were observed and little penetration of the substrate occurred. The stages seen conform to the life cycle pattern suggested by Lechevalier et al. (I968).

\section{DISCUSSION}

Many applications of scanning electron microscopy to biological material have not involved working magnifications in excess of 5000 times. By making use of the large depth of focus provided by this instrument, much information has been obtained at this and much lower magnifications. However, for microbes as small as actinomycetes magnifications below 5000 times provide limited information, and greater magnification is often needed. To obtain informative pictures of actinomycetes at higher magnifications specimens must be prepared by appropriate methods, and it must be borne in mind that the reactions of different strains to fixation and dessication under vacuum are not uniform. In addition, the microscope should be operated under conditions that provide high resolution combined with a reduced but sufficient depth of focus.

The results described here illustrate further the considerable range of form of the actinomycetes. Many of their structures have analogues in the fungi. Thus the sporangium of Actinoplanes is similar to that of fungi in the order Chytridales whilst that of 
Planomonospora is not unlike the operculate ascus of certain Discomycetes. The predominance of structural features in the classification of actinomycetes seems likely to continue, although they can be successfully allied with information from other techniques such as cell wall analysis (Lechevalier \& Lechevalier, I965; Williams, Davies \& Cross, 1968). Scanning electron microscopy in addition to giving more accurate information about known characters also provides new ones.

The observations of some of the genera in this study raise questions about their taxonomic status. Both Actinopycnidium and Actinosporangium produce chains of spores or fragments and are peculiar only in the tendency for these to be concentrated in local sites. Cell wall analysis data of Becker, Lechevalier \& Lechevalier (1965) and Yamaguchi (1965) place these genera in the same group as Streptomyces, and the observations made here are consistent with this suggestion. The genera Microellobosporia and Microechinospora spp. appear to be very closely related, differing only in the number of spores in the sporangium, and Microechinospora spp. could be reclassified as a species of Microellobosporia. Spore shape indicates an affinity between Actinobifida and Thermoactinomyces. These genera have a number of other common features including formation of spores on both substrate mycelium and aerial mycelium, development of spores within a sporangium, heat resistance of the spores and resistance to novobiocin (Cross et al. I968). In morphology and life cycle, Sporichthya is unlike any previously described actinomycete. From its morphological features alone it is difficult to place, having similarities with Streptomyces (chains of cells on aerial growth), Nocardia (transitory mycelial phase) and certain sporangium-forming genera (flagellate cells). Lechevalier et al. (I 968) placed it in the family Streptomycetaceae, finding its cell wall composition to be similar to Streptomyces.

The author wishes to thank Mr D. Stratton and Mr C. J. Veltkamp for technical advice and assistance.

\section{REFERENCES}

Baldacci, E., Locci, R. \& Rogers Locci, J. (1966). Production of 'granules' by Actinomycetales. Giornale di Microbiologia I4, I73-I 84 .

BARnes, G. \& NEVE, N. F. B. (I968). Examination of plant surface microflora by the scanning electron microscope. Transactions of the British Mycological Society 5I, 8I I-8I 2.

Becker, B., Lechevalier, M. P. \& Lechevalier, H. A. (1965). Chemical composition of cell wall preparations from strains of various form-genera of aerobic actinomycetes. Applied Microbiology I3, 236-243.

Couch, J. N. (1955). A new genus and family of the Actinomycetales, with a revision of the genus Actinoplanes. Journal of Elisha Mitchell Scientific Society 7x, I48-1 55.

Cross, T., Lechevalier, M. P. \& Lechevalier, H. (I963). A new genus of the Actinomycetales Microellobosporia gen. nov. Journal of General Microbiology 31, 421-430.

Cross, T., Walker, P. D. \& Gould, G. W. (1968). Thermophilic actinomycetes producing resistant endospores. Nature, London 220, 352-354.

DietZ, A. \& MATHEws, J. (1969). Scanning electron microscopy of selected members of the Streptomyces hygroscopicus group. Applied Microbiology 18, 694-696.

Echlin, P. (I968). The use of the scanning reflection electron microscope in the study of plant and microbial material. Journal of the Royal Microscopical Society 88, 407-418.

Gray, T. R. G. (1967). Stereoscan electron microscopy of soil micro-organisms. Science, New York I55, I 668-I670.

Greenhalgh, G. N. \& Evans, L. V. (I968). The developing ascospores wall of Hypoxylon fragiforme. Journal of the Royal Microscopical Society 88, 545-556. 
Hagen, C. A., Hawrylewicz, E. J., Anderson, B. J., Tolkacz, V. K. \& Cephus, M. L. (1968). Use of the scanning electron microscope for viewing bacteria in soil. Applied Microbiology 16, 932934 .

HAWKER, L. E. (1968). Wall ornamentation of ascospores of species of Elaphomyces as shown by the scanning electron microscope. Transactions of the British Mycological Society 51, 493-498.

HaWker, L. E. \& GoOday, M. A. (I968). Development of the zygospore wall in Rhizopus sexualis (Smith) Callen. Journal of General Microbiology 54, I 3-20.

JONES, D. (1968). Surface features of fungal spores as revealed in a scanning electron microscope. Transactions of the British Mycological Society 51, 608-6Io.

Konev, Y. Y. Tsyganov, V. A., Minbaev, R. \& Morosov, V. M. (1965). Isolation of a new genus of actinomycetes. IV Scientific Congress of the Leningrad Scientific Research Institute for Antibiotics, pp. 80-82. (In Russian.)

Krasilnikov, N. A. (1962). A new genus ray of fungus--Actinopycnidium nov.gen. of family Actinomycetaceae. Mikrobiologiya 3r, 249-253. (In Russian.)

Krasilnikov, N. A. \& AGRE, N.S. (I965). The brown group of Actinobifida chromogena n.sp. Mikrobiologiya 34, 284-29I. (In Russian.)

Krasilnikov, N. A. \& Tsi-Shen, J. (I96I). Actinosporangium-a new genus of the Actinoplanaceae family. Izvestiya Akademii Nauk SSSR ser. Biol. I96I, I I3-I I6. (In Russian.)

LecheValier, H. A. \& HolberT, P. E. (I965). Electron microscopic observation of the sporangial structure of a strain of Actinoplanes. Journal of Bacteriology 89, 2 1 7-222.

LecheValier, H. \& Lechevalier, M. P. (1965). Classification des Actinomycetes aérobies basée sur leur morphologie et leur composition chimique. Annales de l'Institut Pasteur, Paris 108, 662-673.

Lechevalier, M. P. \& Lechevalier, H. A. (1957). A new genus of the Actinomycetales; Waksmania gen. nov. Journal of General Microbiology 17, I04-I I I.

Lechevalier, M. P., Lechevalier, H. A. \& Holbert, P. E. (I968). Sporichthya, un nouveau genre de Streptomycetaceae. Annales de l'Institut Pasteur, Paris 114, 277-286.

Murphy, J. A. \& Campbell, L. L. (1969). Surface features of Bacillus polymyxa spores as revealed by scanning electron microscopy. Journal of Bacteriology 98, 737-743.

Old, K. M. \& Robertson, W. M. (I969). Examination of conidia of Cochiobolus sativus recovered from natural soil using transmission and scanning electron microscopy. Transactions of the British Mycological Society 53, 217-221.

Small, E. B. \& MarszaleK, D. S. (I969). Scanning electron microscopy of fixed, frozen and dried protozoa. Science, New York $\mathbf{1 6 3}$, $1064-1065$.

Thiemann, J. E. \& Beretta, G. (I968). A new genus of the Actinoplanaceae: Planobispora gen. nov. Archiv für Microbiologie 62, I 57-I 66.

Thiemann, J. E., Pagani, H. \& Beretta, G. (1967a). A new genus of the Actinoplanaceae: Dactylosporangium gen. nov. Archiv für Mikrobiologie 58, 42-52.

Thiemann, J. E., Pagani, H. \& Beretta, G. (1967 $b$ ). A new genus of the Actinoplanaceae: Planomonospora, gen.nov. Giornale di Microbiologia $\mathbf{5}, 27-38$.

Waksman, S. A. (1961). The Actinomycetes, Vol. 2. Classification, Identification and Description of Genera and Species. Baltimore: The Williams and Wilkins Co.

Williams, S. T. \& Davies, F. L. (1967). Use of a scanning electron microscope for the examination of actinomycetes. Journal of General Microbiology 48, 171-177.

Williams, S. T., Davies, F. L. \& Cross, T. (I968). Identification of genera of the Actinomycetales. In Identification Methods for Microbiologists, Part B, p. III. Edited by B. M. Gibbs \& D. A. Shapton. London \& New York: Academic Press.

Williams, S. T. \& Sharples, G. P. (1970). A comparative study of spore formation in two Streptomyces species. Microbios 5, 17-26.

YAMAGUCHI, T. (I965). Comparison of the cell-wall composition of morphologically distinct actinomycetes. Journal of Bacteriology 89, 444-453. 
Journal of General Microbiolog.', Vol. 62, No. I

Plate 1
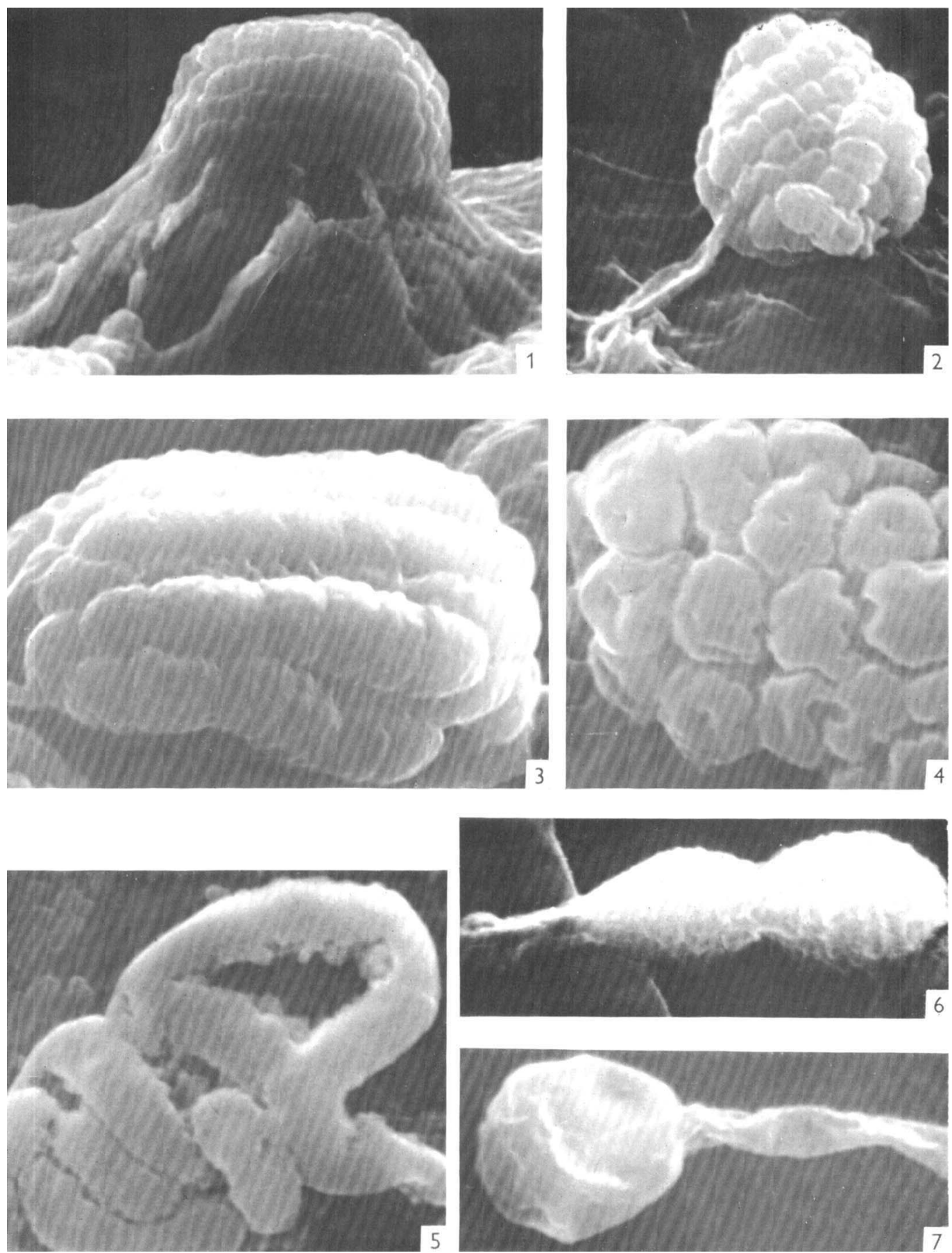

$S T$ WIILIAMS

(Facing p. 721 
Journal of General Microbiology, Vol. 62, No. I

Plate 2
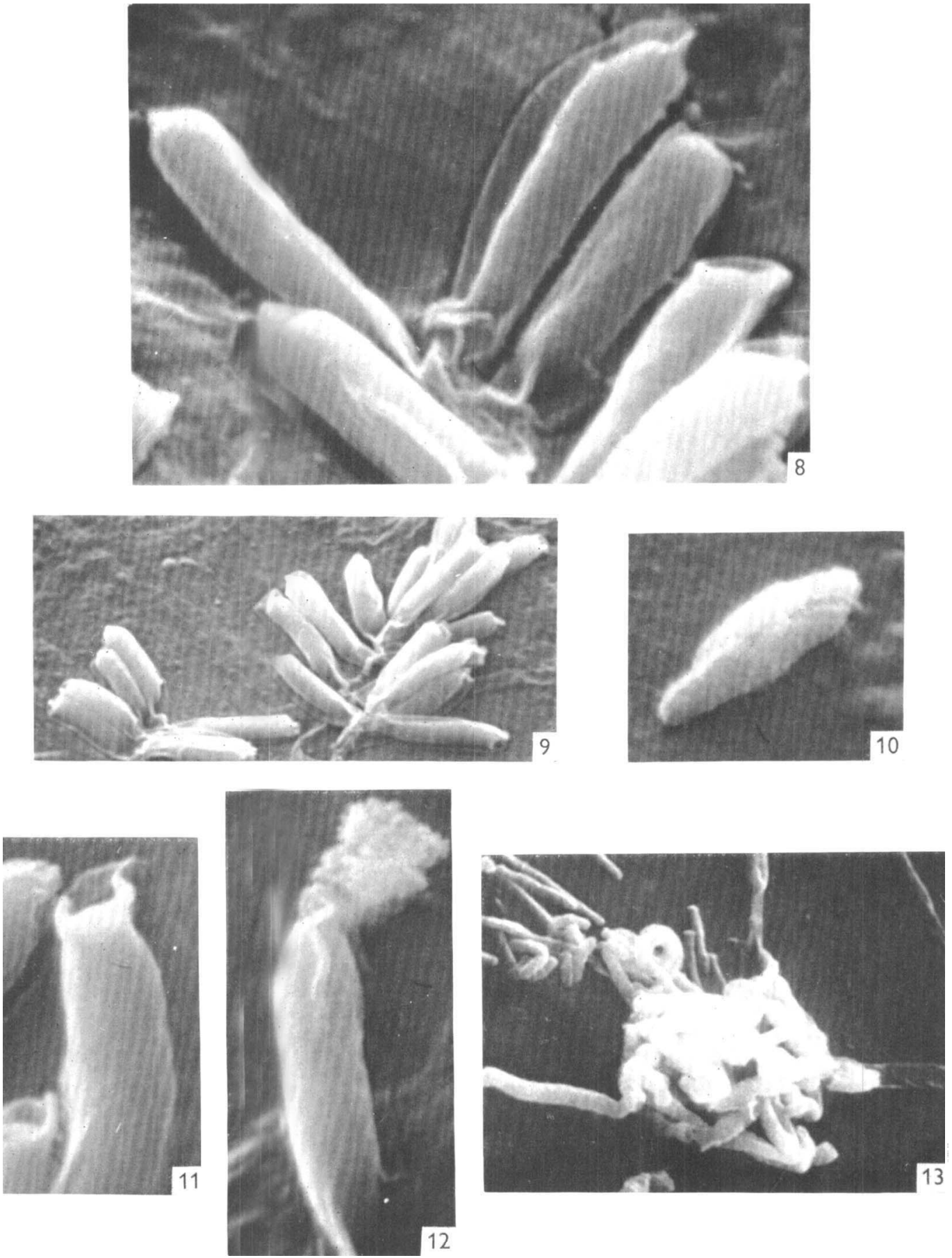

S. T. WILLIAMS 
Journal of General Microbiology, Vol. 62, No. I

Plate 3
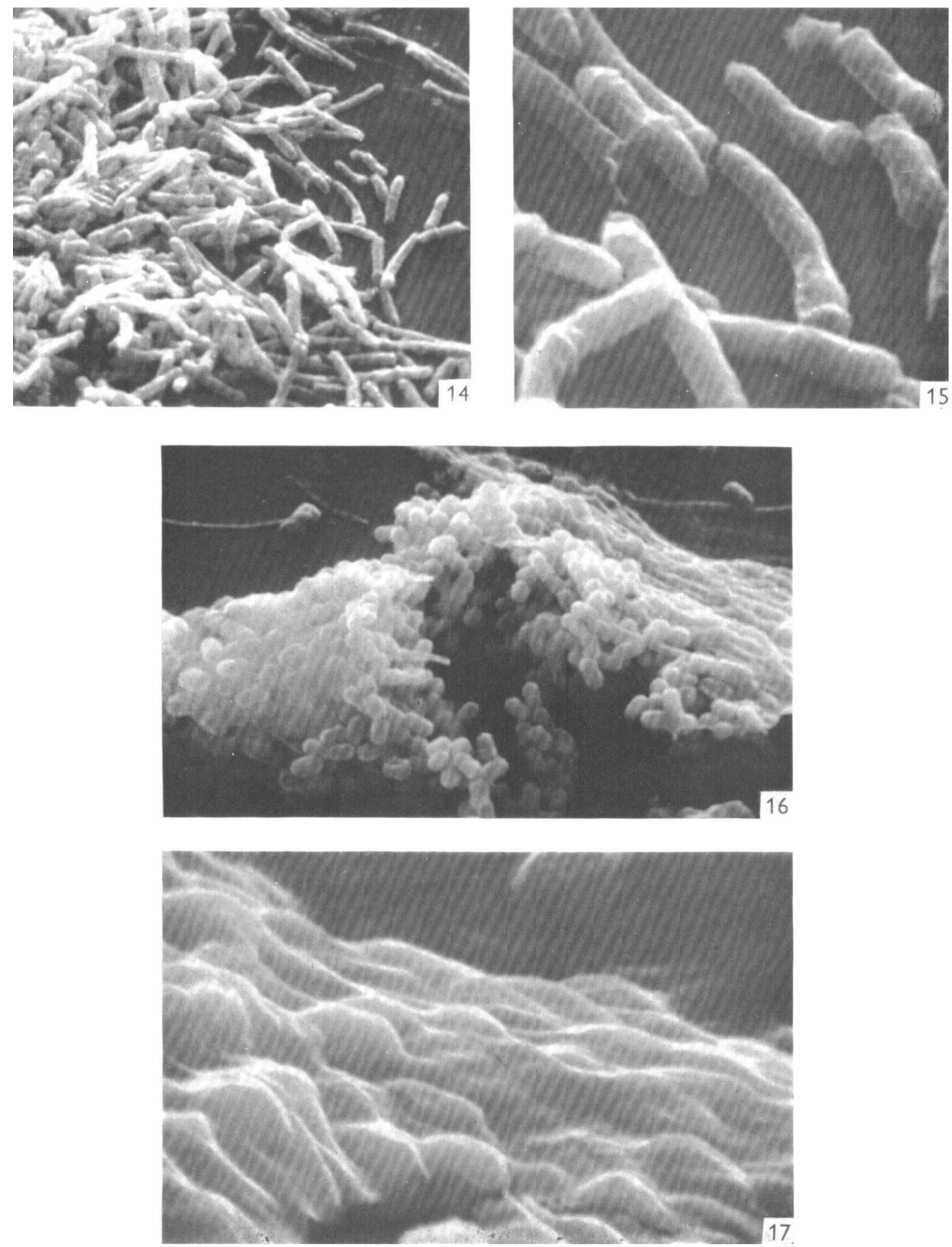

S. T. WILLIAMS 

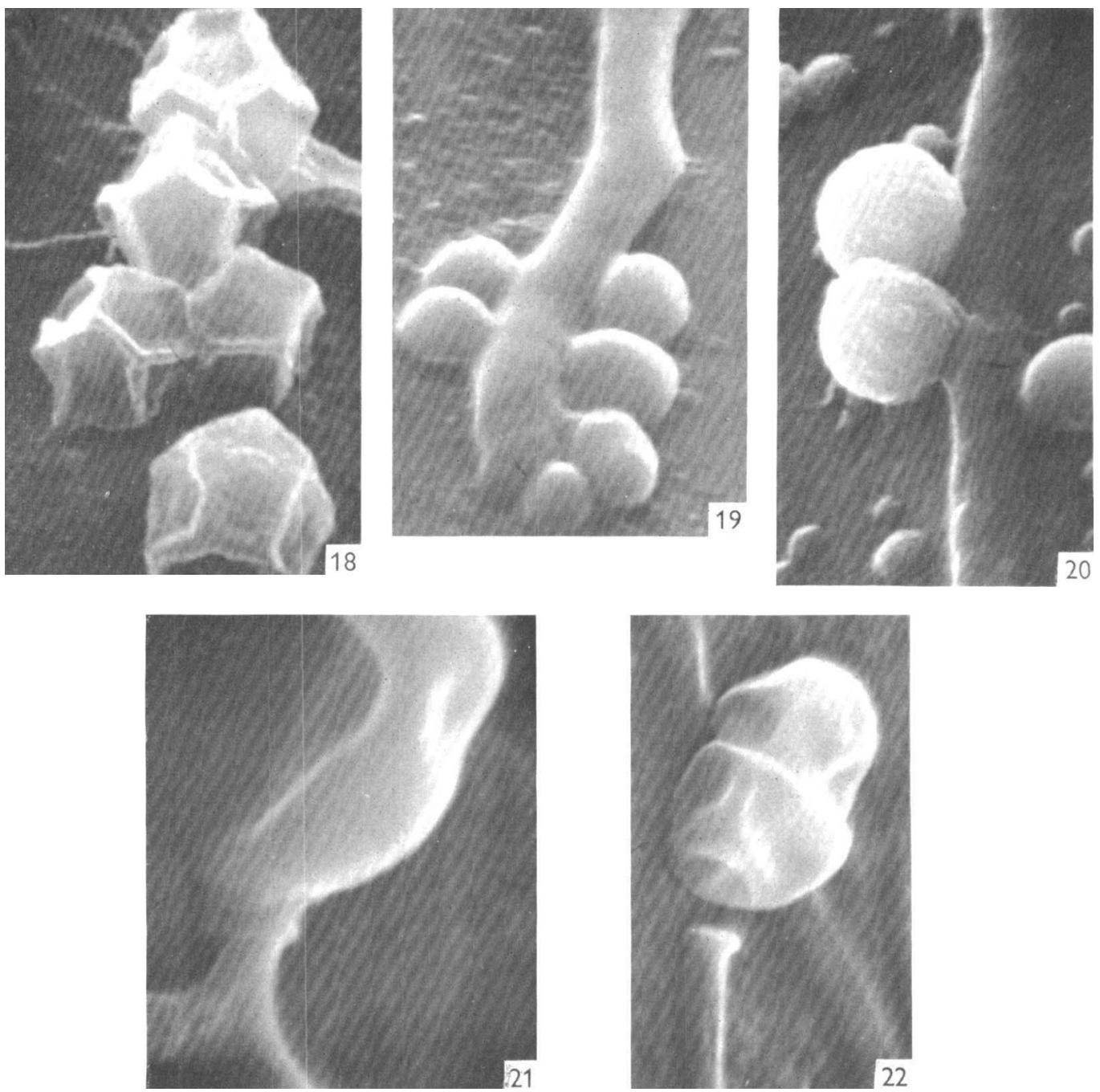

S. T. WILLIAMS 

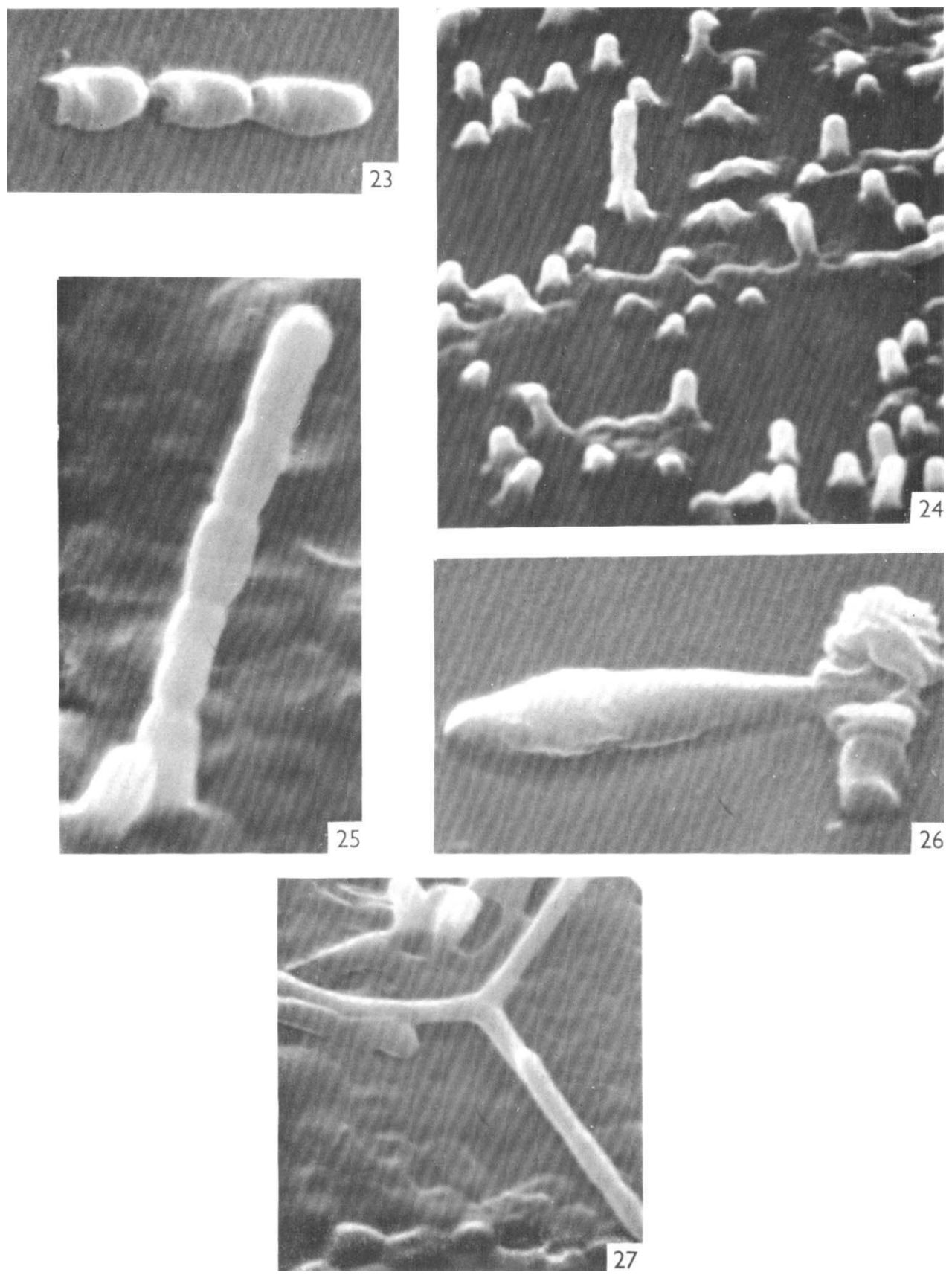

S. T. WIIIIAMS 